\title{
DETERMINING THE SET OF REPRESENTATIVE VARIABLES OF REAL-WORLD DRIVING CYCLE OF BUS: A CASE STUDY OF HANOI
}

\section{Yen-Lien T. Nguyen}

Faculty of Transport Safety and Environment, University of Transport and Communications, No 3 Cau Giay Street, Hanoi, Vietnam

\section{ARTICLE INFO}

TYPE: Research Article

Received: $25 / 12 / 2019$

Revised: $12 / 2 / 2020$

Accepted: 15/2/2020

Published online: 28/5/2020

https://doi.org/10.25073/tcsj.71.4.1

* Corresponding author

Email: nylien@utc.edu.vn; Tel: 0972079992

\begin{abstract}
This paper analysed the real-world driving data to determine the representative parameters of driving cycle for the purpose of the typical driving cycle development of bus in Hanoi. The realworld driving data of bus in Hanoi were collected by using the Global positioning system technique with $1 \mathrm{~Hz}$ data update rate. The real-world driving data of fifteen bus routes in the inner city were collected continuously, on weekdays as well as at weekends. The data, then, were used to calculate 33 kinematics parameters reflecting the realistic driving characteristics, including vehicle-specific power. The hierarchical agglomerative clustering method was used to determine a minimal set of representative variables from the 33 kinematics parameters. The 14 representative parameters of the real-world driving cycle of bus in Hanoi were determined.
\end{abstract}

Keywords: driving characteristics, driving cycle, HAC, VSP, Hanoi, bus

C 2020 University of Transport and Communications

\section{INTRODUCTION}

The transport system in Hanoi is undergoing a rapid development process to meet the strong growth rate of the city in recent years. However, due to very high vehicle density during a poor transportation infrastructure, the traffic jams are still happening frequently. Hence, transport sector is estimated to be one of the main causes of air pollution in Hanoi, in which buses are the main emission source of particulate matter (PM) and black carbon (BC), these pollutants can cause effects strongly on human health. Therefore, air pollutants emission from the bus system in Hanoi must be controlled closely. 
Emission factor (EF) is a useful tool to estimate the amount of pollutants released from a specific source; hence, it is widely used in the emission inventory. However, there are many factors can impact the EF. For vehicles, these factors include the vehicle type and age, air pollution control technologies, the fuel type and quality, the vehicle operation conditions, inspection and maintenance (I/M) conditions, and ambient air conditions. Therefore, each country should use the country-specific emission factor (CSEF) instead of values adopted from other countries to reduce the uncertainty level in national emission inventories.

The vehicle emission measurement under the controlled condition in laboratories based on the local driving cycle is the ideal approach for CSEF development [5]. According to this approach, the local typical driving cycle must be developed first. In the driving cycle development, the kinematics parameters of the driving cycle are used as basis to capture the realistic driving characteristics and are entered into the typical driving cycle. They are also used as assessment criteria to choose a typical driving cycle. However, in almost all previous studies, the selected parameters mainly reflect the driving characteristics, without parameters reflects well vehicle emission characteristics as vehicle specific power (VSP) parameter [8, 12]. In addition, most of previous studies often use driving cycle parameters following the experience of previous studies without presenting an explanation of their choice, as in [7], [13], [15], [9] and so on. Meanwhile, the study of Torp et al. (2013) showed that on the different data sets, selected parameters could be very different although the data mining method are the same. Therefore, for the purpose of the typical driving cycle development to support for inventorying the emission of bus in Hanoi, I proposed using VSP as one of driving cycle parameters. After that, I used the hierarchical agglomerative clustering method to determine the set of representative variables of driving cycle based on the real-world driving. These representative variables can be used to develop a typical driving cycle or an eco-driving model for bus in Hanoi in next studies.

\section{METHODOLOGY}

The overall methodology used to extract the representative variables of driving cycle for bus in Hanoi is presented in Fig.1.

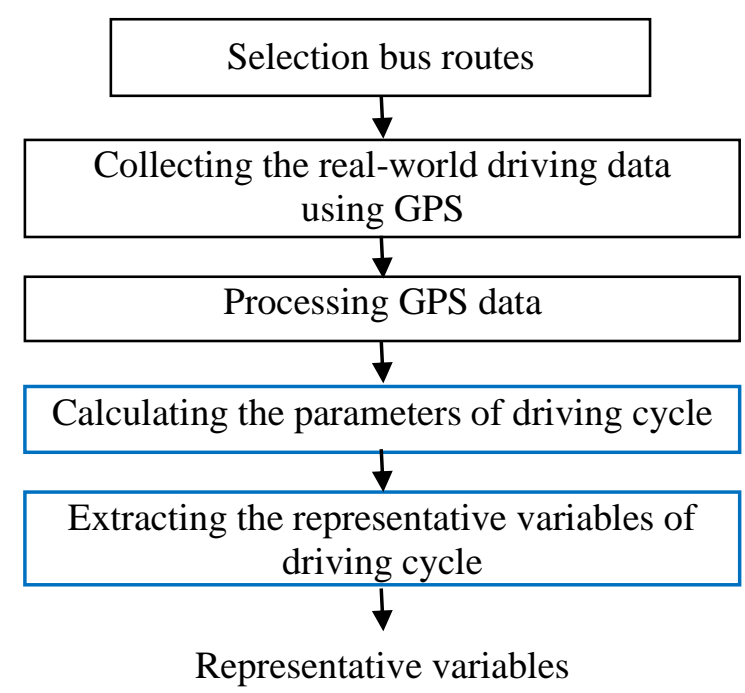

Figure 1. Overall process extracting the representative variables of driving cycle. 
This study is part of our overall research to develop the CSEF for buses in Vietnam. In our study, a GPS device (Garmin etrex vista $\mathrm{HCx}$ ) with the frequency resolution of $1 \mathrm{~Hz}$ was used to collect real-world driving data on the fifteen bus routes in urban Hanoi. The realworld driving data collection was described in detail in our previous study, see [11]. In this paper, I only focus on the representative variables extraction of driving data to achieve our overall study purpose as blue highlighted in Fig.1 above.

\subsection{Calculating the parameters of driving cycle}

The collected GPS after processing was used to calculate the kinematics parameters of the real-world driving data of bus in Hanoi. These parameters are presented in Table 1. The definitions of these parameters are applied to a velocity profile consisting of $n$ data rows of time $t_{i}$ in second, and speed $v_{i}$ in $\mathrm{kph}$, with $1 \leqslant \mathrm{i} \leqslant \mathrm{n}$, as presented in Table $2[1,2,14,17]$.

Table 1. The parameters of driving cycle.

\begin{tabular}{|c|c|c|c|}
\hline No. & Parameter & Abbreviations & Units \\
\hline 1 & Total time & T_total & $\mathrm{sec}$ \\
\hline 2 & Acceleration time & T_acc & $\mathrm{sec}$ \\
\hline 3 & Deceleration time & T_dec & $\mathrm{sec}$ \\
\hline 4 & Cruising time & T_c & $\mathrm{sec}$ \\
\hline 5 & Creeping time & T_cr & $\mathrm{sec}$ \\
\hline 6 & Idle time $($ speed $=0$ ) & $\mathrm{T} \_\mathrm{i}$ & $\mathrm{sec}$ \\
\hline 7 & Time proportion of idling mode & $P \_i$ & $\%$ \\
\hline 8 & Time proportion of acceleration mode & P_a & $\%$ \\
\hline 9 & Time proportion of deceleration mode & P_d & $\%$ \\
\hline 10 & Time proportion of cruising mode & $P_{-} c$ & $\%$ \\
\hline 11 & Time proportion of creeping mode & P_cr & $\%$ \\
\hline 12 & Total distance & Dist & $\mathrm{km}$ \\
\hline 13 & Average trip speed & $\mathrm{V}_{1}$ & $\mathrm{kph}$ \\
\hline 14 & Average driving speed & $\mathrm{V}_{2}$ & $\mathrm{kph}$ \\
\hline 15 & Maximum speed & $\mathrm{V}_{\max }$ & $\mathrm{kph}$ \\
\hline 16 & Standard deviation of speed & Vsd & $\mathrm{kph}$ \\
\hline 17 & 95th percentile of speed & P95V & $\mathrm{kph}$ \\
\hline 18 & Maximum acceleration & a_max & $\mathrm{m} \cdot \mathrm{sec}^{-2}$ \\
\hline 19 & Minimum acceleration & a_min & m.sec ${ }^{-2}$ \\
\hline 20 & Acceleration average & a_av & m. $\sec ^{-2}$ \\
\hline 21 & Average positive acceleration & a_pos_av & m.sec ${ }^{-2}$ \\
\hline 22 & Average negative acceleration & a_neg_av & m.sec ${ }^{-2}$ \\
\hline 23 & Root mean square of acceletration & RMSA & m.sec ${ }^{-2}$ \\
\hline 24 & 95th percentile of positive acceleration & P95PosAcc & m.sec ${ }^{-2}$ \\
\hline 25 & 95th percentile of negative acceleration & P95NegAcc & m.sec ${ }^{-2}$ \\
\hline 26 & Standard deviation of acceleration & Acc_sd & m. $\sec ^{-2}$ \\
\hline 27 & Number of stops & N_stop & - \\
\hline 28 & Number of stops per km & N_rate & $/ \mathrm{km}$ \\
\hline 29 & Maximum VSP & $\mathrm{VSP}_{\max }$ & W.kg-1 \\
\hline 30 & Minimum VSP & $\mathrm{VSP}_{\text {min }}$ & W. $\mathrm{kg}^{-1}$ \\
\hline 31 & Average positive VSP & VPSpos_av & W.kg-1 \\
\hline 32 & Average negative VSP & VSPneg_av & W. $\mathrm{kg}^{-1}$ \\
\hline 33 & Positive kinetic energy & PKE & m.sec ${ }^{-2}$ \\
\hline
\end{tabular}




\section{Parameters}

Total distance

$$
\text { Dist }=\left(\mathrm{t}_{2}-\mathrm{t}_{1}\right) \frac{\mathrm{v}_{1}}{3.6}+\sum_{\mathrm{i}=2}^{\mathrm{n}}\left(\mathrm{t}_{\mathrm{i}}-\mathrm{t}_{\mathrm{i}-1}\right) \frac{\mathrm{v}_{\mathrm{i}}}{3.6}
$$

Total time

$$
\text { T_total }=\mathrm{t}_{2}-\mathrm{t}_{1}+\sum_{\mathrm{i}=2}^{\mathrm{n}}\left(\mathrm{t}_{\mathrm{i}}-\mathrm{t}_{\mathrm{i}-1}\right)
$$

Cruising time

$$
\begin{aligned}
\mathrm{T}_{-} \mathrm{c} & =\left\{\begin{array}{ll}
\mathrm{t}_{2}-\mathrm{t}_{1} & \left(\left|\mathrm{a}_{1}\right|<0.1 \mathrm{~m} \mathrm{sec}^{-2} \text { and } \mathrm{v}_{1}>5 \mathrm{~m} \mathrm{sec}^{-1}\right) \\
0 & (\text { else })
\end{array}\right\} \\
& +\sum_{\mathrm{i}=2}^{\mathrm{n}}\left\{\begin{array}{ll}
\mathrm{t}_{\mathrm{i}}-\mathrm{t}_{\mathrm{i}-1} & \left(\left|\mathrm{a}_{\mathrm{i}}\right|<0.1 \mathrm{~m} \mathrm{sec}^{-2} \text { and } \mathrm{v}_{\mathrm{i}}>5 \mathrm{~m} \mathrm{sec}^{-1}\right) \\
0 & (\text { else })
\end{array}\right\}
\end{aligned}
$$

Creeping time

$$
\begin{aligned}
\mathrm{T}_{-} \mathrm{cr} & =\left\{\begin{array}{ll}
\mathrm{t}_{2}-\mathrm{t}_{1} & \left(\left|\mathrm{a}_{1}\right|<0.1 \mathrm{~m} \mathrm{sec}^{-2} \text { and } \mathrm{v}_{1}<5 \mathrm{~m} \mathrm{sec}^{-1}\right) \\
0 & (\text { else })
\end{array}\right\} \\
& +\sum_{\mathrm{i}=2}^{\mathrm{n}}\left\{\begin{array}{cc}
\mathrm{t}_{\mathrm{i}}-\mathrm{t}_{\mathrm{i}-1} & \left(\left|\mathrm{a}_{\mathrm{i}}\right|<0.1 \mathrm{~m} \mathrm{sec}^{-2} \text { and } \mathrm{v}_{\mathrm{i}}<5 \mathrm{~m} \mathrm{sec}^{-1}\right) \\
0 & (\text { else })
\end{array}\right\}
\end{aligned}
$$

Acceleration time

$$
\mathrm{T}_{-} \mathrm{acc}=\left\{\begin{array}{ll}
\mathrm{t}_{2}-\mathrm{t}_{1} & \left(\mathrm{a}_{1}>0.1 \mathrm{~m} \mathrm{sec}^{-2}\right) \\
0 & (\text { else })
\end{array}\right\}+\sum_{\mathrm{i}=2}^{\mathrm{n}}\left\{\begin{array}{ll}
\mathrm{t}_{\mathrm{i}}-\mathrm{t}_{\mathrm{i}-1}\left(\mathrm{a}_{\mathrm{i}}>0.1 \mathrm{~m} \mathrm{sec}^{-2}\right) \\
0 & \text { (else) }
\end{array}\right\}
$$

Decceleration time

$$
\mathrm{T}_{-} \operatorname{dec}=\left\{\begin{array}{ll}
\mathrm{t}_{2}-\mathrm{t}_{1} & \left(\mathrm{a}_{1}<-0.1 \mathrm{~m} \mathrm{sec}^{-2}\right) \\
0 & (\text { else })
\end{array}\right\}+\sum_{\mathrm{i}=2}^{\mathrm{n}}\left\{\begin{array}{ll}
\mathrm{t}_{\mathrm{i}}-\mathrm{t}_{\mathrm{i}-1}\left(\mathrm{a}_{\mathrm{i}}<-0.1 \mathrm{~m} \mathrm{sec}^{-2}\right) \\
0 & (\text { else })
\end{array}\right\}
$$

Idling time

$$
\mathrm{T}_{-} \text {idle }=\left\{\begin{array}{ll}
\mathrm{t}_{2}-\mathrm{t}_{1}\left(\mathrm{v}_{1}=0 \text { and } \mathrm{a}_{1}=0\right) \\
0 & (\text { else })
\end{array}\right\}+\sum_{\mathrm{i}=2}^{\mathrm{n}}\left\{\begin{array}{ll}
\mathrm{t}_{\mathrm{i}}-\mathrm{t}_{\mathrm{i}-1}\left(\mathrm{v}_{1}=0 \text { and } \mathrm{a}_{1}=0\right) \\
0 & (\text { else })
\end{array}\right\}
$$

Time proportion of cruising mode

$$
\mathrm{P}_{-} \mathrm{c}=\frac{\mathrm{T}_{-} \mathrm{c}}{\mathrm{T} \text {-total }} .100 \%
$$

Time proportion of creeping mode

$$
\mathrm{P}_{-} \mathrm{cr}=\frac{\mathrm{T}_{-} \mathrm{cr}}{\mathrm{T}_{-} \text {total }} .100 \%
$$

Time proportion of acceleration mode

$$
\mathrm{P}_{-} \text {acc }=\frac{\mathrm{T}_{-} \mathrm{acc}}{\mathrm{T} \text { total }} .100 \%
$$


Time proportion of deceleration mode

$$
\mathrm{P}_{-} \text {dec }=\frac{\mathrm{T}_{-} \text {dec }}{\mathrm{T}_{-} \text {total }} .100 \%
$$

Time proportion of idling mode

$$
\mathrm{P}_{-} \text {stop }=\frac{\mathrm{T}_{-} \text {idle }}{\mathrm{T} \text { total }} \cdot 100 \%
$$

Average trip speed

$$
\mathrm{V}_{1}=3.6 \frac{\text { Dist }}{\mathrm{T}_{-} \text {total }}
$$

Average driving speed

$$
\mathrm{V}_{2}=3.6 \frac{\text { Dist }}{\mathrm{T}_{-} \text {drive }}
$$

Standard deviation of speed

$$
\mathrm{V}_{-} \mathrm{sd}=\sqrt{\frac{1}{\mathrm{n}-1} \sum_{\mathrm{i}=1}^{\mathrm{n}} \mathrm{v}_{\mathrm{i}}^{2}}
$$

Acceleration average

$$
\text { a_av }=\frac{1}{\mathrm{~N}} \sum_{\mathrm{i}=1}^{\mathrm{n}} \mathrm{a}_{\mathrm{i}} \quad(\text { with } \mathrm{N}=\mathrm{T} \text {.total })
$$

Average positive acceleration

$$
\text { a_pos_av }=\left(\sum_{\mathrm{i}=1}^{\mathrm{n}}\left\{\begin{array}{l}
\left.1 \text { if } \mathrm{a}_{\mathrm{i}}>0\right) \\
0(\mathrm{else})
\end{array}\right\}\right)^{-1} \times \sum_{1}^{\mathrm{n}}\left\{\begin{array}{l}
\mathrm{a}_{\mathrm{i}}\left(\text { if } \mathrm{a}_{\mathrm{i}}>0\right) \\
0(\text { else })
\end{array}\right\}
$$

Average negative acceleration

$$
\text { a_neg_av }=\left(\sum_{i=1}^{n}\left\{\begin{array}{l}
1\left(\text { if } a_{i}<0\right) \\
0(\text { else })
\end{array}\right\}\right)^{-1} \times \sum_{1}^{n}\left\{\begin{array}{l}
a_{i}\left(\text { if } a_{i}<0\right) \\
0(\text { else })
\end{array}\right\}
$$

Standard deviation of acceleration

$$
\text { Acc_sd }=\sqrt{\frac{1}{\mathrm{n}-1} \sum_{\mathrm{i}=1}^{\mathrm{n}} \mathrm{a}_{\mathrm{i}}^{2}}
$$

Number of stops

$$
\mathrm{N} \_s t o p=\sum_{\mathrm{i}=1}^{\mathrm{n}}\left\{\begin{array}{l}
1\left(\left\{\mathrm{v}_{\mathrm{i}}=0 \wedge \mathrm{a}_{\mathrm{i}}=0\right\} \wedge\left\{\mathrm{v}_{\mathrm{i}} \neq 0 \vee \mathrm{a}_{\mathrm{i}} \neq 0\right\}\right) \\
0(\text { else })
\end{array}\right.
$$

Stops per km

$$
\text { N_rate }=1000 \frac{\text { N_stop }}{\text { Dist }}
$$

Positive kinetic energy

$$
\text { PKE }=\frac{1}{\operatorname{dist}} \times \sum_{i=2}^{n}\left\{\begin{array}{cc}
v_{i}^{2}-v_{i-1}^{2} & \left(\text { if } v_{i}>v_{i-1}\right) \\
0 & (\text { else })
\end{array}\right\}
$$


Root mean square of acceletration

$$
\begin{aligned}
& \text { RMSA }=\sqrt{\frac{1}{\mathrm{~T}} \int_{0}^{\mathrm{T}} \mathrm{a}^{2} \cdot \mathrm{dt}}=\sqrt{\frac{1}{\mathrm{~N}} \cdot \sum_{\mathrm{i}=1}^{\mathrm{N}} \mathrm{a}_{\mathrm{i}}^{2}} \\
& \text { where: } \mathrm{N}=\mathrm{T}=\mathrm{T}_{-} \text {total }
\end{aligned}
$$

Vehicle specific power

$$
\mathrm{VSP}=\left\{\mathrm{a} \cdot(1+\varepsilon)+\mathrm{g} \cdot \operatorname{grade}+\mathrm{g} \cdot \mathrm{C}_{\mathrm{R}}\right\} \cdot \mathrm{v}+\frac{1}{2} \rho_{\mathrm{a}} \frac{\mathrm{C}_{\mathrm{D}} \cdot \mathrm{A}}{\mathrm{m}} \mathrm{v}^{3}
$$

Where: $\mathrm{v}$ - vehicle speed (assuming no headwind) ; a - vehicle acceleration; $\varepsilon$ - mass factorg $(\sim 0.1)$; grade - road grade ( $\sim 0$ for urban road); $\mathrm{m}$ - vehicle mass; $\mathrm{g}$ - acceleration of gravity $\left(9.81 \mathrm{~m} / \mathrm{s}^{2}\right) ; \mathrm{C}_{\mathrm{R}}$ - coefficient of rolling resistance $(0.008 \div 0.013) ; \mathrm{C}_{\mathrm{D}}$ - drag coefficient $(0.5 \div 0.7) ; \mathrm{A}$ - frontal area of the vehicle; $\rho_{\mathrm{a}}$ - ambient air density $\left(\sim 1.2 \mathrm{~kg} / \mathrm{m}^{3}\right)$.

In which, the frontal area of the vehicle is calculated as follows [4]:

$$
\mathrm{A}=(\mathrm{H}-\mathrm{GC}) . \mathrm{W} \cdot 0.93
$$

Where: $\mathrm{H}$ - vehicle height (m); W - vehicle width (m); GC - ground clearance (m).

\subsection{Extracting the representative variables of driving cycle}

After the GPS data processing step, I collected 317 trip segments as detail described in [10]. All of 317 trip segments were used to calculate the real-world driving cycle parameters following to the definition as presented in Table 1. Therefore, I obtained the dataset consist of 317 rows and 33 columns in proportion to 317 trips and 33 driving cycle parameters. This dataset was used to extract the representative variable of driving cycle by using the hierarchical agglomerative clustering (HAC) method. The IBM SPSS Statistics software used to perform this clustering. In this study, I used the furthest neighbor algorithm to measure the distance between two clusters, called complete-link measurement, and used the absolute value of Pearson correlation coefficient to measure the distance between variables. Using the Pearson correlation coefficient measurement is more suitable than others because the driving cycle parameters are very different in the value range and units. In addition, some driving kinematic parameters are calculated based on others, hence, between these parameters can have mutual correlation. This cause the results of searching for the typical driving cycle can be misleading $[8,16]$. Therefore, using the absolute value of Pearson correlation coefficient (r) as the distance measure to agglomerate parameters into a cluster would be a suitable approach.

\section{RESULTS AND DISCUSSION}

\subsection{Real-world driving characteristics of bus in Hanoi}

Using the definition of driving cycle parameters as mentioned above, I calculated the driving cycle parameters of 317 trip segments. The characteristics of real-world driving data of bus in urban Hanoi are presented in Table 3 below.

As can be seen in Table 3, the operation of the bus system in Hanoi has not yet reached high efficiency. The average speed of $16.6 \mathrm{kph}$ is smaller than the one of other countries, for example bus in Beijing of $20.7 \mathrm{kph}$ [8], bus in the Braunschweig city of $22.6 \mathrm{kph}$ [2]. 
Transport and Communications Science Journal, Vol. 71, Issue 4 (05/2020), 317-327

Table 3. Real-world driving characteristics of bus in Hanoi.

\begin{tabular}{|c|c|c|c|c|c|}
\hline Parameters & Average $^{(*)}$ & Units & Parameters & Average $^{(*)}$ & Units \\
\hline T_total & 3823.9 & $\mathrm{sec}$ & a_max & 3.5 & $\mathrm{~m} \cdot \mathrm{sec}^{-2}$ \\
\hline T_acc & 1408.6 & sec & a_min & -3 & $\mathrm{~m} \cdot \mathrm{sec}^{-2}$ \\
\hline T_dec & 1452.5 & $\mathrm{sec}$ & a_av & 0 & $\mathrm{~m} \cdot \mathrm{sec}^{-2}$ \\
\hline T_c & 320.2 & $\mathrm{sec}$ & a_pos_av & 0.6 & $\mathrm{~m} \cdot \mathrm{sec}^{-2}$ \\
\hline T_cr & 326.4 & $\mathrm{sec}$ & a_neg_av & -0.5 & $\mathrm{~m} \cdot \mathrm{sec}^{-2}$ \\
\hline$T_{-} \mathrm{i}$ & 325.1 & $\mathrm{sec}$ & RMSA & 0.6 & $\mathrm{~m} \cdot \mathrm{sec}^{-2}$ \\
\hline$P_{-} \mathrm{i}$ & 0.1 & $\%$ & P95PosAcc & 1.5 & $\mathrm{~m} \cdot \mathrm{sec}^{-2}$ \\
\hline P_a & 0.4 & $\%$ & P95NegAcc & -1.3 & $\mathrm{~m} \cdot \mathrm{sec}^{-2}$ \\
\hline P_d & 0.4 & $\%$ & Acc_sd & 0.6 & $\mathrm{~m} \cdot \mathrm{sec}^{-2}$ \\
\hline P_c & 0.1 & $\%$ & N_stop & 26.7 & - \\
\hline P_cr & 0.1 & $\%$ & N_rate & 1.6 & $/ \mathrm{km}$ \\
\hline Dist & 17.5 & $\mathrm{~km}$ & VSPmax & 32.5 & $\mathrm{~W} \cdot \mathrm{kg}^{-1}$ \\
\hline $\mathrm{V}_{1}$ & 16.6 & $\mathrm{kph}$ & VSPmin & -25.2 & $\mathrm{~W} \cdot \mathrm{kg}^{-1}$ \\
\hline $\mathrm{V}_{2}$ & 18.1 & $\mathrm{kph}$ & VSPpos_av & 2.6 & W. $\mathrm{kg}^{-1}$ \\
\hline $\mathrm{V}_{\max }$ & 45.2 & $\mathrm{kph}$ & VSPneg_av & -2.7 & $\mathrm{~W} \cdot \mathrm{kg}^{-1}$ \\
\hline $\mathrm{V}_{\mathrm{sd}}$ & 10.4 & $\mathrm{kph}$ & PKE & 0.4 & $\mathrm{~m} \cdot \mathrm{sec}^{-2}$ \\
\hline $\mathrm{P} 95 \mathrm{~V}$ & 32.9 & $\mathrm{kph}$ & & & \\
\hline
\end{tabular}

Note: ${ }^{(*)}$ the average value of 317 values in proportion to 317 trips.

\subsection{Clusters of driving cycle parameters}

The calculated dataset above was used to reduce the number of parameters by using the SPSS software with options for the HAC method as described in above. The agglomeration schedule is presented in Table 4.

As shown in Table 4, in the first stage, the variable 23 (RMSA) and the variable 26 (Acc_sd) were combined in the first cluster because the Pearson correlation coefficient between them is highest, $r=1$.

The HAC algorithm does not give the conclusions of cluster numbers, therefore, the user must do it. At present, there is no clear rule for determining cluster numbers [6]. In this study, the more clusters numbers are, the more the representative parameters of driving cycle are, and the better capturing the features of realistic driving patterns is. Therefore, the representative driving cycle parameters should be kept more. However, this can cause the iteration process to find the typical driving cycle becomes an infinite loop. In this study, I proposed two cases to agglomeration variables into clusters, one case with $r \geq 0.8$, called Case 1 , and the other with $r \geq 0.7$, called Case 2 . The number of final clusters were determined based on the agglomeration schedule of 33 driving cycle variables, see Table 4 . For Case 1 , the clustering process only stop at stage of 13 with the correlation coefficient of 0.84 , the number of final clusters are 20 clusters. For Case 2, the clustering process only stop at stage of 17 with the correlation coefficient of 0.764 , the number of final clusters are 16 clusters. The number of final clusters retained are the number of representative parameters of driving cycle. However, Dist and T_total variables do not reflect the real-world driving pattern, they depend mainly on the infrastructure of bus routes, therefore, these two parameters cannot be 
Transport and Communications Science Journal, Vol. 71, Issue 4 (05/2020), 317-327

used to describe the real-world driving characteristics $[1,16]$. Therefore, the representative parameters of driving cycle determined for two cases are described in Table 5.

Table 4 . The agglomeration schedule of 33 driving cycle variables.

\begin{tabular}{|c|c|c|c|c|c|c|}
\hline \multirow{2}{*}{ Stage } & \multicolumn{2}{|c|}{ Cluster Combined } & \multirow{2}{*}{ Coefficients } & \multicolumn{2}{|c|}{ Stage Cluster First Appears } & \multirow{2}{*}{ Next Stage } \\
\hline & Cluster 1 & Cluster 2 & & Cluster 1 & Cluster 2 & \\
\hline 1 & 23 & 26 & 1.000 & 0 & 0 & 5 \\
\hline 2 & 21 & 33 & .963 & 0 & 0 & 9 \\
\hline 3 & 13 & 14 & .958 & 0 & 0 & 14 \\
\hline 4 & 31 & 32 & .955 & 0 & 0 & 16 \\
\hline 5 & 22 & 23 & .955 & 0 & 1 & 9 \\
\hline 6 & 2 & 3 & .943 & 0 & 0 & 8 \\
\hline 7 & 6 & 7 & .938 & 0 & 0 & 17 \\
\hline 8 & 1 & 2 & .910 & 0 & 6 & 21 \\
\hline 9 & 21 & 22 & .908 & 2 & 5 & 13 \\
\hline 10 & 4 & 10 & .901 & 0 & 0 & 28 \\
\hline 11 & 5 & 11 & .900 & 0 & 0 & 14 \\
\hline 12 & 27 & 28 & .871 & 0 & 0 & 24 \\
\hline 13 & 21 & 24 & .840 & 9 & 0 & 18 \\
\hline 14 & 5 & 13 & .786 & 11 & 3 & 24 \\
\hline 15 & 16 & 17 & .785 & 0 & 0 & 23 \\
\hline 16 & 25 & 31 & .782 & 0 & 4 & 18 \\
\hline 17 & 6 & 8 & .764 & 7 & 0 & 19 \\
\hline 18 & 21 & 25 & .674 & 13 & 16 & 26 \\
\hline 19 & 6 & 9 & .668 & 17 & 0 & 27 \\
\hline 20 & 18 & 29 & .650 & 0 & 0 & 25 \\
\hline 21 & 1 & 12 & .622 & 8 & 0 & 30 \\
\hline 22 & 19 & 30 & .558 & 0 & 0 & 25 \\
\hline 23 & 15 & 16 & .519 & 0 & 15 & 29 \\
\hline 24 & 5 & 27 & .426 & 14 & 12 & 27 \\
\hline 25 & 18 & 19 & .282 & 20 & 22 & 26 \\
\hline 26 & 18 & 21 & .216 & 25 & 18 & 28 \\
\hline 27 & 5 & 6 & .208 & 24 & 19 & 29 \\
\hline 28 & 4 & 18 & .170 & 10 & 26 & 31 \\
\hline 29 & 5 & 15 & .035 & 27 & 23 & 30 \\
\hline 30 & 1 & 5 & .003 & 21 & 29 & 32 \\
\hline 31 & 4 & 20 & .003 & 28 & 0 & 32 \\
\hline 32 & 1 & 4 & .000 & 30 & 31 & 0 \\
\hline
\end{tabular}

As can be seen in Table 5, the extracted representative variables in this study include most of the representative variables that were determined in other studies. In addition, the number of kept variables in this study is higher. Therefore, the ability of maintaining integrity of the real-world driving characteristics during the development of the typical driving cycle is also better. In addition, to demonstrate the necessity of representative variables determination of driving cycle before developing a typical driving cycle, I used the clustering method used by Torp et al (2013) for the real-world driving data of bus in Hanoi; the extraction result of representative variables is presented in "Case 0" in Table 5. Comparison between three cases, I can find that the number of variables kept in Case 1 and Case 2 are higher than Case 0 . 
Therefore, the ability of capturing the real-world driving characteristics of Case 1 and Case 2 are better than Case 0. In addition, as said in Section 2.2, between variables can have mutual correlation causing the results of searching for the typical driving cycle can be misleading. In other words, using the Pearson correlation coefficient as a distance measure between clusters to determine the representative variables of real-world driving data is a suitable approach.

Table 5. The representative parameters of driving cycle.

\begin{tabular}{|c|c|c|c|c|c|c|}
\hline \multirow{3}{*}{ Parameters } & \multicolumn{3}{|c|}{ In this study } & \multicolumn{3}{|c|}{ Other studies } \\
\hline & \multirow[t]{2}{*}{ Case $1^{\text {(a) }}$} & \multirow[t]{2}{*}{ Case $2^{\text {(a) }}$} & \multirow[t]{2}{*}{ Case $0^{(\mathrm{c})}$} & \multirow{2}{*}{$\begin{array}{c}\text { Brady et al. } \\
\text { (2013) } \\
\text { (b) }\end{array}$} & \multicolumn{2}{|c|}{$\begin{array}{c}\text { Torp et al } \\
\text { (2013) }\end{array}$} \\
\hline & & & & & (c) & (b) \\
\hline P_c & $\checkmark$ & $\checkmark$ & $\checkmark$ & & $\checkmark$ & $\checkmark$ \\
\hline P_cr & $\checkmark$ & & $\checkmark$ & & & \\
\hline$P_{-} i$ & $\checkmark$ & $\checkmark$ & & $\checkmark$ & $\checkmark$ & $\checkmark$ \\
\hline $\mathrm{P}_{-} \mathrm{a}$ & $\checkmark$ & & & & & \\
\hline P_d & $\checkmark$ & $\checkmark$ & & & $\checkmark$ & \\
\hline $\mathrm{V}_{1}$ & $\checkmark$ & $\checkmark$ & & $\checkmark$ & & $\checkmark$ \\
\hline $\mathrm{V}_{\max }$ & $\checkmark$ & $\checkmark$ & & & & $\checkmark$ \\
\hline $\mathrm{V}_{\mathrm{sd}}$ & $\checkmark$ & & $\checkmark$ & & & \\
\hline P95V & $\checkmark$ & $\checkmark$ & & & & \\
\hline a_max & $\checkmark$ & $\checkmark$ & $\checkmark$ & $\checkmark$ & $\checkmark$ & $\checkmark$ \\
\hline a_min & $\checkmark$ & $\checkmark$ & $\checkmark$ & $\checkmark$ & $\checkmark$ & $\checkmark$ \\
\hline a_av & $\checkmark$ & $\checkmark$ & $\checkmark$ & & & \\
\hline PKE & $\checkmark$ & $\checkmark$ & & & & \\
\hline P95NegAcc & $\checkmark$ & & $\checkmark$ & & & \\
\hline N_rate & $\checkmark$ & $\checkmark$ & & $\checkmark$ & $\checkmark$ & $\checkmark$ \\
\hline $\mathrm{VSP}_{\max }$ & $\checkmark$ & $\checkmark$ & & $\checkmark$ & & $\checkmark$ \\
\hline $\mathrm{VSP}_{\min }$ & $\checkmark$ & $\checkmark$ & & & & \\
\hline $\mathrm{VSP}_{\text {pos_av }}$ & $\checkmark$ & $\checkmark$ & & & & \\
\hline N-stop & & & $\checkmark$ & & & \\
\hline Total $^{(d)}$ & 18 & 14 & 8 & 10 & 8 & 14 \\
\hline
\end{tabular}

Notes. ${ }^{(a)}$ Hierarchical agglomerative clustering method with the distance measure of Pearson correlation coefficient; (b) Regression analysis method; (c) Hierarchical agglomerative clustering method with the distance measure proposed by Torp et al (2013);

(d) Total selected representative variables including ones which are not used in this study.

In addition, as presented in Table 5, the kept variables in Case 0 are very different from ones determined in [16] although the used clustering method is the same but for two different real-world driving datasets. To make the decision about the choice of the representative variables according to Case 1 or Case 2, I brought these variables into the computer program developed to construct the typical driving cycle that has been published in a separate paper [11]. For two running times in proportion to two cases, I found that using the 18 representative variables of Case 1 failing to make the loop stop, it becomes an infinite loop. 
Therefore, I proposed using the 14 representative variables of Case 2 for the purpose of typical driving cycle development.

\section{CONCLUSION}

Determining the least number of driving parameters that can well capture the real-world driving characteristics and take them in the typical driving cycle is very necessary to develop the CSEF and the eco-driving model. However, the real-world driving characteristics can be different from one region to another. Therefore, using the representative variables by inheriting the previous study results that those determined based on the set of different driving data could cause losing important information. It is very necessary to determine the representative variables of the driving data based on the driving data set used to develop the driving cycle. Therefore, in this study, the real-world driving data of 15 bus routes in Hanoi were used to determine the representative variables of driving cycle for purposing the typical driving cycle development. The HAC algorithm using the distance measure of Pearson correlation coefficient used to extract the representative variables from 33 initial variables. A total of 14 representative variables were selected. This study has affirmed that the selected variables could be very different, even when applying the same data mining method on different dataset. Hence, future investigations should determine the driving cycle representative variables based on their own input data instead of following the experience of previous studies.

\section{ACKNOWLEDGMENT}

This research is funded by University of Transport and Communications (UTC) under grant number T2020-MT-002.

\section{REFERENCES}

[1]. A. Ashtari, E. Bibeau and S. Shahidinejad, Using Large Driving Record Samples and a Stochastic Approach for Real-World Driving Cycle Construction: Winnipeg Driving Cycle Transportation Science, 48 (2014) 170 - 183. http://dx.doi.org/10.1287/trsc.1120.0447

[2]. T. J. Barlow, S. Latham, I. S. McCrae and P. G. Boulter, A reference book of driving cycles for use in the measurement of road vehicle emissions, Department for Transport, UK, 2009.

[3]. J. Brady, M. O'Mahony, The development of a driving cycle for the greater Dublin area using a large database of driving data with a stochastic and statistical methodology, Proceedings of the ITRN2013, Trinity College Dublin, 2013.

[4]. K. N. Edward, G. Robert, Fuel consumption modeling of conventional and advanced technology vehicles in the physical emission rate estimator (PERE), Office of Transportation and Air Quality, EPA, 2005.

[5]. V. Franco, M. Kousoulidou, M. Muntean, L. Ntziachristos, S. Hausberger, P. Dilara, Road vehicle emission factors development: A review, Atmospheric Environment, 70 (2013) 84 - 97. http://dx.doi.org/10.1016/j.atmosenv.2013.01.006

[6]. Hoang Trong, Chu Nguyen Mong Ngoc, Phan tich du lieu nghien cuu voi SPSS, NXB Hong Duc, 2008.

[7]. W. T. Hung, H. Y. Tong, C. P. Lee, K. Ha, L. Y. Pao, Development of a practical driving cycle construction methodology: A case study in Hong Kong, Transportation Research part D: Transport and Environment, 12 (2007) 115-128. https://doi.org/10.1016/j.trd.2007.01.002

[8]. J. Lai, L. Yu, G. Song, P. Guo, X. Chen, Development of City-Specific Driving Cycles for Transit Buses Based on VSP Distributions: Case of Beijing, Journal of Transportation Engineering, 139 (2013) 749-757. http://dx.doi.org/10.1061/(ASCE)TE.1943-5436.0000547 
[9]. P. Lipar, I. Strnad, M. Česnik, T. Maher, Development of urban driving cycle with GPS data post $\begin{array}{lllll}\text { processing, } & \text { Promet-Traffic\&Transportation, } & 28 & \text { (2016) 353-364. }\end{array}$ http://dx.doi.org/10.7307/ptt.v28i4.1916

[10].Y.-L. T. Nguyen, N.-D. Bui, T.-D. Nghiem, A.-T. Le, GPS data processing for driving cycle development in Hanoi, Vietnam, Journal of Engineering Science and Technology (2019). (in press).

[11].Y.-L. T. Nguyen, T.-D. Nghiem, A.-T. Le, N.-D. Bui, Development of the typical driving cycle for buses in Hanoi, Vietnam, Journal of the Air \& Waste Management Association, 69 (2019) 423437. https://doi.org/10.1080/10962247.2018.1543736

[12].Y. Qi, A. Padiath, Q. Zhao, L. Yu, Development of operating mode distributions for different types of roadways under different congestion levels for vehicle emission assessment using MOVES, Journal of the Air \& Waste Management Association, 66 (2016) 1003-1011. https://doi.org/10.1080/10962247.2016.1194338

[13].W. Saleh, R. Kumar, H. Kirby, P. Kumar, Real world driving cycle for motocycles in Edinburgh, Transportation Research part D: Transport and Environment, 14 (2009) 326-333. https://doi.org/10.1016/j.trd.2009.03.003

[14].Q. Shi, Y. Zheng, R. Wang, Y. Li, The study of a new method of driving cycles construction, Procedia Engineering, 16 (2011) 79-87. https://doi.org/10.1016/j.proeng.2011.08.1055

[15].H. Y. Tong, H. D. Tung, W. T. Hung, H. V. Nguyen, Development of driving cycles for motorcycles and light-duty vehicles in Vietnam, Atmospheric Environment, 45 (2011) 5191-5199. https://doi.org/10.1016/j.atmosenv.2011.06.023

[16].E. Torp and P. Önnegren, Driving cycle generation using statistical analysis and Markov chain, Department of Electrical Engineering, Likopings University, Sweden, 2013.

[17].F. Zheng, J. Li, H. van Zuylen, C. Lu, Influence of driver characteristics on emissions and fuel consumption, Transportation Research Procedia, $27 \quad$ (2017) 624-631. https://doi.org/10.1016/j.trpro.2017.12.142 